ARTICLE

DOI: $10.1038 / s 41467-018-06917-4$

\title{
Effect of hydrophobic cations on the oxygen reduction reaction on single-crystal platinum electrodes
}

\author{
Tomoaki Kumeda ${ }^{1}$, Hiroo Tajiri ${ }^{2}$, Osami Sakata (iD ${ }^{3}$, Nagahiro Hoshi ${ }^{1}$ \& Masashi Nakamura (iD ${ }^{1}$
}

Highly active catalysts for the oxygen reduction reaction are essential for the widespread and economically viable use of polymer electrolyte fuel cells. Here we report the oxygen reduction reaction activities of single-crystal platinum electrodes in acidic solutions containing tetraalkylammonium cations with different alkyl chain lengths. The high hydrophobicity of a tetraalkylammonium cation with a longer alkyl chain enhances the oxygen reduction reaction activity. The activity on $\mathrm{Pt}(111)$ in the presence of tetra-n-hexylammonium cation is eight times as high as that without this cation, which is comparable to the activities on $\mathrm{Pt}_{3} \mathrm{Co}(111)$ and $\mathrm{Pt}_{3} \mathrm{Ni}$ (111) electrodes. Hydrophobic cations and their hydration shells destabilize the adsorbed hydroxide and adsorbed water. The hydrophobic characteristics of non-specifically adsorbed cations can prevent the adsorption of poisoning species on the platinum electrode and form a highly efficient interface for the oxygen reduction reaction.

\footnotetext{
${ }^{1}$ Department of Applied Chemistry and Biotechnology, Graduate School of Engineering, Chiba University, Yayoi-cho 1-33, Inage-ku, Chiba 263-8522, Japan. ${ }^{2}$ Research and Utilization Division, Japan Synchrotron Radiation Research Institute/SPring-8, Kouto 1-1-1, Sayo-gun, Hyogo 679-5148, Japan. ${ }^{3}$ Synchrotron X-ray Group and Synchrotron X-ray station at Spring-8, National Institute for Materials Science, Kouto 1-1-1, Sayo-gun, Hyogo 679-5148, Japan.

Correspondence and requests for materials should be addressed to M.N. (email: mnakamura@faculty.chiba-u.jp)
} 
T he development of highly active catalysts for the oxygen reduction reaction (ORR) is a prominent issue in terms of decreasing Pt loading in cathode catalysts for polymer electrolyte fuel cells (PEFCs). Model electrocatalysts with atomically well-defined surfaces have provided detailed information regarding activation sites, optimal atomic arrangement, and the surface composition of catalysts, which have been applied to nanomaterials for practical use. In the case of Pt-based materials, the introduction of heterometals drastically improves ORR activity, depending on the surface structure ${ }^{1-3}$. PtM $(\mathrm{M}=\mathrm{Ni}, \mathrm{Co}$, etc.) bimetal alloys perturb the density of state (DOS) of the dband and compress the lattice strain of the surface layer ${ }^{4,5}$. Consequently, the ORR activities on $\operatorname{PtM}(111)$ are increased by one order of magnitude as high as that of $\mathrm{Pt}(111)$ electrode $^{6,7}$. In many heterogeneous catalysts, the catalytic activity has a volcanoshaped relationship with the atomic arrangement and alloy composition of the substrate. The variation of the d-band DOS of the substrate modifies the adsorption energy of the reaction products and the intermediate species. Therefore, the center position of the d-band DOS strongly correlates with the ORR activity. $\mathrm{Pt}_{3} \mathrm{Ni}$ and $\mathrm{Pt}_{3} \mathrm{Co}$ are located near the top in the volcanoshaped dependency between the activity and the d-band center ${ }^{4}$. The introduction of step and kink structures also activates the ORR; the high-index planes of Pt give the maximum activity for the ORR on the surfaces with 3-4 atomic rows of (111) terrace ${ }^{8-10}$. The catalyst development through substrate modification has reached a maturity stage, and other approaches are required for further enhancement of the ORR activity.

The activity of electrochemical reactions is affected by the solvent and electrolyte ions as well as the substrate. At the electrode/electrolyte interface, such solution species construct the electric double layer (EDL), which governs the ORR activity on Pt surfaces significantly. It is well known that strongly adsorbed anions, such as halide and sulfate ions, on the Pt surface inhibit the ORR severely ${ }^{11-13}$. The adsorbed hydroxide $\left(\mathrm{OH}_{\mathrm{ad}}\right)$ species is formed on Pt surfaces in electrolytic solutions containing ions that weakly interact with $\mathrm{Pt}$ surfaces ${ }^{13}$. The stability of $\mathrm{OH}_{\mathrm{ad}}$ depends on the surface structure and on the electronic state of the substrate ${ }^{4,14-16}$. Since $\mathrm{OH}_{\mathrm{ad}}$ is also an inhibitor for the ORR, the control of $\mathrm{OH}_{\mathrm{ad}}$ is a key factor in activating the ORR.

In the EDL, some hydrated cations located at the outer Helmholtz plane (OHP) are stabilized as non-specifically adsorbed species through non-covalent interactions, such as hydrogen bonds and electrostatic interactions ${ }^{17}$. Non-covalent interactions in the EDL shift the adsorption equilibrium and the phase transition potential of the adsorbed layer ${ }^{18}$. In alkaline media, the ORR activity of $\mathrm{Pt}(111)$ is improved exponentially as the hydration energy of the OHP cations decreases; the activity in $\mathrm{CsOH}$ is one order of magnitude higher than that in $\mathrm{LiOH}^{19}$. Cations with a high affinity toward oxygen species, such as $\mathrm{Li}^{+}$, strongly stabilize $\mathrm{OH}_{\mathrm{ad}}{ }^{20}$, which then deactivates the ORR. Therefore, appropriate control of the structure and hydrophobicity of the interfacial cations can improve ORR activity.

In PEFCs, which use proton-exchange membranes, the control of hydrophobicity is necessary in acidic solutions. In this study, we focus on tetraalkylammonium (TAA) cations of which the hydrophobicity and interfacial structure can be controlled by the alkyl chain length. Variation of the alkyl chain length can change the hydration structure of $\mathrm{TAA}^{+}$dramatically ${ }^{21,22}$. We have evaluated the ORR activity on single-crystal Pt electrodes in acidic solutions containing $\mathrm{TAA}^{+}$with different alkyl chains lengths. The interfacial structures have also been determined by in situ X-ray scattering and infrared (IR) spectroscopy measurements.

\section{Results}

Electrochemical characterization. We used four types of $\mathrm{TAA}^{+}$ with different alkyl chains lengths $(n)$ : tetramethylammonium $\left(\mathrm{TMA}^{+}\right) n=1$, tetraethylammonium $\left(\mathrm{TEA}^{+}\right) n=2$, tetra- $n$ butylammonium $\left(\mathrm{TBA}^{+}\right) \quad n=4$, and tetra- $n$-hexylammonium $\left(\mathrm{THA}^{+}\right) n=6$. Figure la shows cyclic voltammograms (CVs) in $0.1 \mathrm{M} \mathrm{HClO}_{4}$ containing $10^{-5} \mathrm{M} \mathrm{TBA}^{+}$and $10^{-6} \mathrm{M} \mathrm{THA}^{+}$. The solubility of $\mathrm{TAA}^{+}$in acidic solution decreases with the increase of alkyl chain length. The concentrations of $\mathrm{TBA}^{+}$and $\mathrm{THA}^{+}$used in this study are approximately equal to the saturation. The CV data show the hydrogen adsorption/desorption region between 0.05 and $0.40 \mathrm{~V}$, the double layer charging/discharging region between $0.40 \mathrm{~V}$ and $0.60 \mathrm{~V}$, and the $\mathrm{Pt}$ oxidation region between $0.60 \mathrm{~V}$ and $0.90 \mathrm{~V}$. In the presence of $\mathrm{TBA}^{+}$and $\mathrm{THA}^{+}$, the onset potentials for the adsorption of hydrogen and $\mathrm{Pt}$ oxidation shift negatively and positively, respectively, whereas the $\mathrm{CV}$ data in solutions containing $10^{-3} \mathrm{M} \mathrm{TMA}^{+}$and $\mathrm{TEA}^{+}$are identical to those without $\mathrm{TAA}^{+}$(Supplementary Figure 1a). This indicates that $\mathrm{TAA}^{+}$with longer alkyl chains affects the adsorption of hydrogen and Pt oxidation, even at low concentration.

No IR absorption band for the alkyl chain of $\mathrm{TAA}^{+}$appears, as shown in Supplementary Figure 2. Previous IR study has revealed that the specific adsorption of $\mathrm{TAA}^{+}$on Pt does not occur above 0 $\mathrm{V}^{23}$. Therefore, the potential shift of hydrogen adsorption is not due to site blocking by specifically adsorbed $\mathrm{TAA}^{+}$. The hydrogen adsorption step is governed by the proton-transfer process in the EDL, which depends on the conformation and hydrogen-bonding interactions of hydration water. Density functional theory (DFT) calculations suggest that hydrogen adsorption energy is affected by proton transfer in the water bilayer ${ }^{24}$. These results indicate that $\mathrm{TBA}^{+}$and $\mathrm{THA}^{+}$located near the electrode induce the reconstruction of interfacial water, and the inhibition of proton transfer in the EDL results in the potential shift for hydrogen adsorption. In the solutions containing $10^{-3} \mathrm{M} \mathrm{TMA}^{+}$and $\mathrm{TEA}^{+}$, no potential shift appears even though the concentrations of $\mathrm{TMA}^{+}$ and $\mathrm{TEA}^{+}$are larger by two or three orders of magnitude than those of $\mathrm{TBA}^{+}$and $\mathrm{THA}^{+}$. Since the enthalpy of hydration water with $\mathrm{TAA}^{+}$is reduced by an increase of the alkyl chain length ${ }^{25}$, the enhancement of hydrophobicity with longer alkyl chains strongly perturbs the interfacial water, changing the equilibrium potentials for the adsorption of hydrogen and $\mathrm{Pt}$ oxidation on $\mathrm{Pt}(111)$.

Figure $1 \mathrm{~b}$ shows linear sweep ORR voltammograms in $0.1 \mathrm{M}$ $\mathrm{HClO}_{4}$ containing $\mathrm{TBA}^{+}$and $\mathrm{THA}^{+}$(voltammograms in $\mathrm{TMA}^{+}$ and $\mathrm{TEA}^{+}$containing solutions are shown in Supplementary Figure. $1 \mathrm{~b})$. The specific activities $\left(j_{\mathrm{k}}\right)$ at $0.90 \mathrm{~V}$ in $\mathrm{TAA}^{+}$-containing solutions are shown in Fig. 1c. The ORR activity increases in the sequence $\mathrm{THA}^{+} \gg \mathrm{TBA}^{+}>\mathrm{TEA}^{+}>\mathrm{TMA}^{+} \approx \mathrm{HClO}_{4}$, and shows a correlation with the hydrophobicity of $\mathrm{TAA}^{+}$. The ORR activity in $\mathrm{THA}^{+}$is eight times greater than that in $0.1 \mathrm{M} \mathrm{HClO}_{4}$. The structural effects of the substrates on the ORR were investigated using the other typical index planes of $\mathrm{Pt}$, as shown in Fig. 1d (CVs and linear sweep ORR voltammograms are shown in Supplementary Figure 3). There is no significant enhancement effect of $\mathrm{THA}^{+}$on $\mathrm{Pt}(100)$ and $\mathrm{Pt}(110)$. However, $\mathrm{THA}^{+}$ enhances the activity on $\operatorname{Pt}(331)=3(111)-(111)$, which gives the highest activity for the ORR on stepped surfaces, by 1.3 times. The specific activities on $\mathrm{Pt}(111)$ and $\mathrm{Pt}(331)$ in $\mathrm{THA}^{+}$-containing solution are comparable with those of $\mathrm{Pt}_{3} \mathrm{Co}$ and $\mathrm{Pt}_{3} \mathrm{Ni}^{6,7}$.

At the initial stage of the $\mathrm{Pt}$ oxidation, the in-plane bending mode $\left(\delta_{\mathrm{PtOH}}\right)$ of $\mathrm{OH}_{\mathrm{ad}}$ is detected by IR spectroscopy. The band intensities of $\delta_{\mathrm{PtOH}}$ at $0.90 \mathrm{~V}$ correlate to the ORR activities $j_{\mathrm{k}}$ at $0.90 \mathrm{~V}$ on single-crystal Pt electrodes, confirming that $\mathrm{OH}_{\mathrm{ad}}$ inhibits the ORR ${ }^{15,16}$. The stability of the hydrogen-bonding network in the coadsorbed $\mathrm{OH}_{\mathrm{ad}}+\mathrm{H}_{2} \mathrm{O}$ layer affects the ORR activity on the (111) terrace, as described in the Discussion section. The approach of hydrophobic cation to the surface may causes the destabilization of 

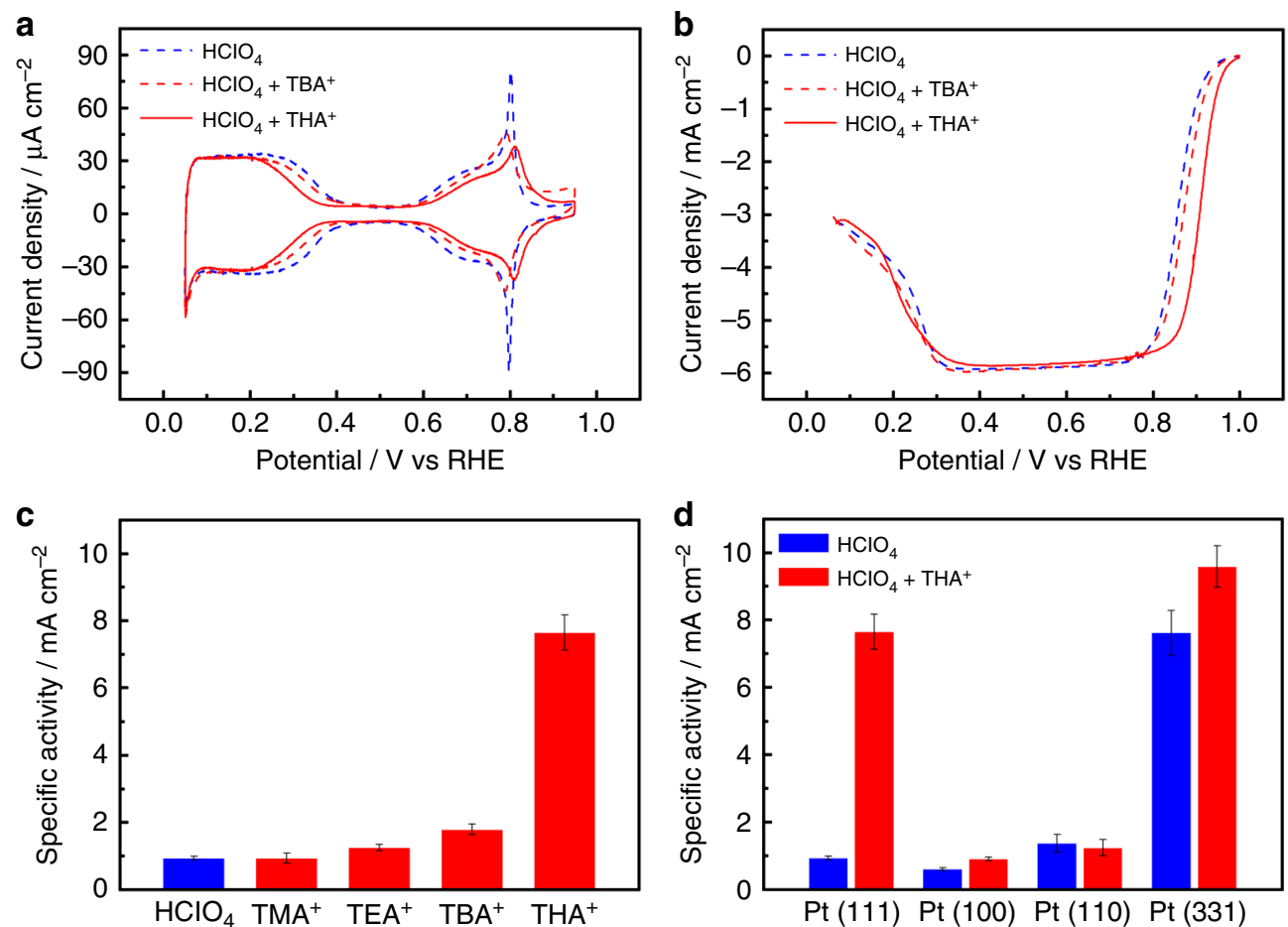

Fig. 1 Electrochemical characterization of platinum electrodes. a Cyclic voltammograms (CVs) and (b) linear sweep oxygen reduction reaction (ORR) voltammograms of $\mathrm{Pt}(111)$ in $0.1 \mathrm{M} \mathrm{HClO}_{4}$ containing $10^{-5} \mathrm{M}$ tetra- $n$-butylammonium cation ( $\mathrm{TBA}^{+}$) and $10^{-6} \mathrm{M}$ tetra- $n$-hexylammonium cation ( $\mathrm{THA}^{+}$). CVs were measured in solutions saturated with Ar. The scanning rate is $0.050 \mathrm{~V} \mathrm{~s}^{-1}$. Linear sweep ORR voltammograms were obtained in the solutions saturated with $\mathrm{O}_{2}$, and the potential was scanned from $0.05 \mathrm{~V}$ in the positive direction. The scanning rate is $0.010 \mathrm{~V} \mathrm{~s}^{-1}$ and the rotation rate of the electrode is $1600 \mathrm{rpm}$. c Specific ORR activities of $\mathrm{Pt}(111)$ in $0.1 \mathrm{M} \mathrm{HClO}_{4}$ containing $10^{-3} \mathrm{M}^{-}$tetramethylammonium cation ( $\mathrm{TMA}^{+}$), $10^{-3} \mathrm{M}^{-}$ tetraethylammonium cation (TEA $\left.{ }^{+}\right), 10^{-5} \mathrm{M} \mathrm{TBA}^{+}$, and $10^{-6} \mathrm{M} \mathrm{THA}^{+}$at $0.9 \mathrm{~V}$ versus reversible hydrogen electrode (RHE). d Specific ORR activities of Pt (111), $\mathrm{Pt}(100), \mathrm{Pt}(110)$, and $\mathrm{Pt}(331)=3(111)-(111)$ in $0.1 \mathrm{M} \mathrm{HClO}_{4}$ with and without $10^{-6} \mathrm{M} \mathrm{THA}+$ at $0.9 \mathrm{~V}$ versus $\mathrm{RHE}$

the $\mathrm{OH}_{\text {ad }}$ layer. Therefore, we determined the interfacial structures and adsorbed species on $\mathrm{Pt}(111)$ in $\mathrm{THA}^{+}$-containing solution in which the degree of activity enhancement was the highest in terms of surface structure and cationic species by using in situ IR spectroscopy and X-ray scattering.

Infrared spectroscopic measurement of adsorbed species. Since the absorption frequency of $\delta_{\mathrm{PtOH}}$ overlaps $v_{\mathrm{ClO}}$ of perchlorate ion, hydrogen fluoride (HF) is used for the IR measurements of $\mathrm{OH}_{\mathrm{ad}}$. Figure 2a shows the IR spectra of $\mathrm{Pt}(111)$ and $\mathrm{THA}^{+}$ modified $\mathrm{Pt}(111)$ in $0.1 \mathrm{M} \mathrm{HClO}_{4}$ and $0.1 \mathrm{M} \mathrm{HF}$. The potentialdependent band at $1050 \mathrm{~cm}^{-1}$ appears above $0.6 \mathrm{~V}$, and is assigned to the in-plane $\delta_{\mathrm{PtOH}}{ }^{15,16,20}$. Figure $2 \mathrm{~b}$ shows the potential dependence of the band intensity for $\delta_{\mathrm{PtOH}}$, and the charge density of $\mathrm{Pt}$ oxidation estimated from the $\mathrm{CV}$ data (Fig. 1a). The onset potential of $\mathrm{OH}$ adsorption shifts positively and the band intensity of $\delta_{\mathrm{PtOH}}$ at $0.90 \mathrm{~V}$ decreases due to the modification with $\mathrm{THA}^{+}$. This result is consistent with the charge density of Pt oxidation in the CV data. The charge density of $\mathrm{Pt}$ oxidation increases above $0.80 \mathrm{~V}$, but the band intensity of $\delta_{\mathrm{PtOH}}$ decreases above $0.80 \mathrm{~V}$. These facts indicate the further oxidation from $\mathrm{PtOH}$ to $\mathrm{PtO}$ above $0.80 \mathrm{~V}^{14}$.

The positive- and negative-absorption bands at 1650 and 1610 $\mathrm{cm}^{-1}$ are assigned to the $\mathrm{HOH}$ bending mode $\left(\delta_{\mathrm{HOH}}\right)$ of nonadsorbed and adsorbed hydrogen bonded water, respectively ${ }^{26,27}$. The $\delta_{\mathrm{HOH}}$ of non-adsorbed water corresponds to those in the liquid phase $\left(1645 \mathrm{~cm}^{-1}\right)$ and the solid phase $\left(1650 \mathrm{~cm}^{-1}\right)$. It is known that $\delta_{\mathrm{HOH}}$ shifts to lower frequency by adsorption on metal surfaces. These frequencies are higher than $\delta_{\mathrm{HOH}}$ for an isolated water monomer $\left(1595 \mathrm{~cm}^{-1}\right.$ from matrix isolation measurements $)^{28}$. Therefore, these water molecules are hydrogen bonded with neighboring oxygen species and electrolyte ions. The generation of $\mathrm{OH}_{\mathrm{ad}}$ above $0.50 \mathrm{~V}$ decreases the coverage of adsorbed water relative to that at the background potential of 0.3 $\mathrm{V}$. The increase in the intensity of $\delta_{\mathrm{HOH}}$ above $0.5 \mathrm{~V}$ also involves the orientation change of water induced by the electrode potential, because the water dipole responds sensitively to the electric field in the EDL. The band intensities of non-adsorbed and adsorbed water are also reduced by the modification with $\mathrm{THA}^{+}$, indicating the decrease of the coverage of $\mathrm{OH}_{\mathrm{ad}}$. No IR bands in the $\mathrm{CH}$ stretching and $\mathrm{CH}$ bending regions appear on $\mathrm{THA}^{+}$modified $\mathrm{Pt}(111)$ between 0.30 and $1.0 \mathrm{~V}$, as shown in Supplementary Figure 2. This fact suggests that the structure of the interfacial $\mathrm{THA}^{+}$is not changed by the electrode potential.

New IR bands appear on $\mathrm{THA}^{+}$-modified $\mathrm{Pt}(111)$ at $1510 \mathrm{~cm}^{-1}$, which are assigned to the $\mathrm{HOH}$ bending mode of adsorbed water monomers at $0.30 \mathrm{~V}$. Since this band overlaps the broad positivegoing band around $1570 \mathrm{~cm}^{-1}$, an accurate absorption frequency is unclear. The red shift from $1510 \mathrm{~cm}^{-1}$ to $1090 \mathrm{~cm}^{-1}$ in $\mathrm{D}_{2} \mathrm{O}$ solvent indicates that these bands are derived from water (Supplementary Figure 4). On $\mathrm{Ni}(111), \mathrm{Rh}(111)$, and $\mathrm{Ru}(0001)$ under ultra-high vacuum condition, the $\delta_{\mathrm{HOH}}$ shifts from $1595 \mathrm{~cm}^{-1}$ (isolated monomer) to $1560 \mathrm{~cm}^{-1}$ (adsorbed monomer) by the adsorption via oxygen lone pair ${ }^{29-31}$. The action spectroscopic method using scanning tunneling microscopy also reveals that the signal for water monomer adsorbed on $\mathrm{Pt}(111)$ appear around $1550 \mathrm{~cm}^{-132}$. At the solid liquid interface, since the interfacial water molecules are cross-linked via a hydrogen-bonding network, the adsorbed monomers are not a stable species on the electrode. The hydrogenbonding structure of water in the EDL is influenced by the OHP 

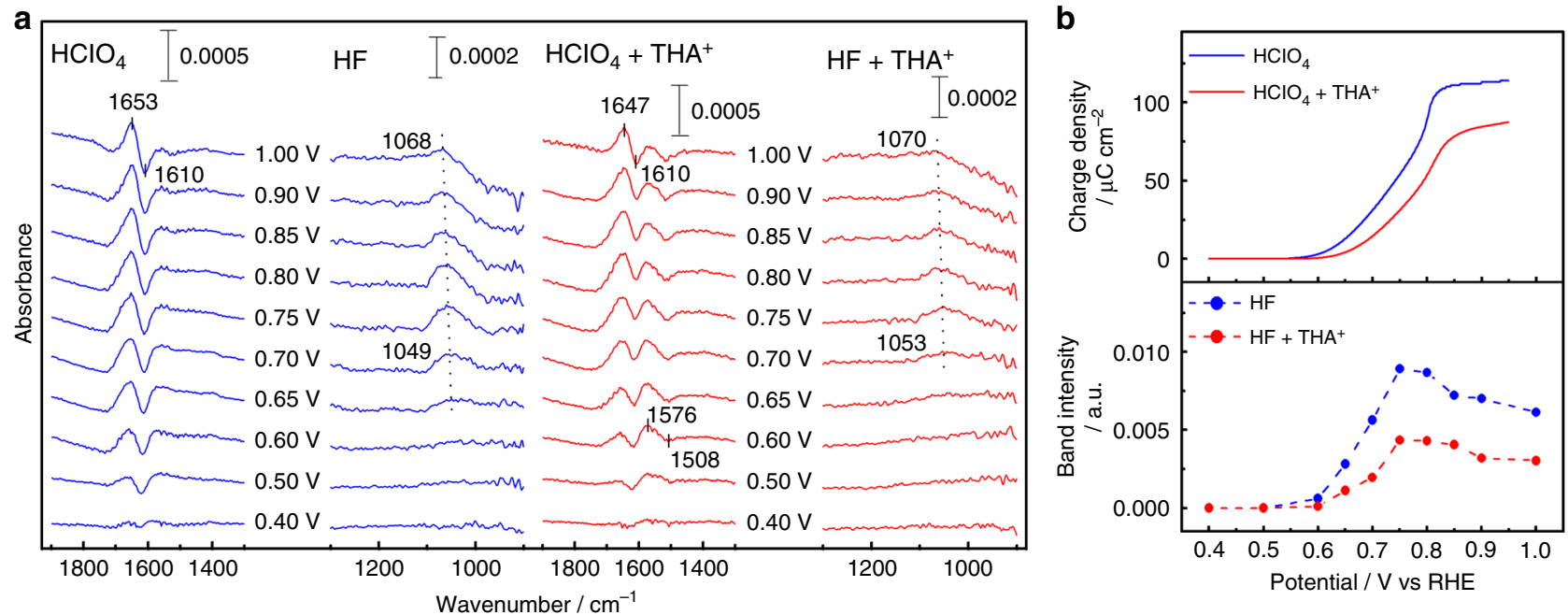

Fig. 2 Infrared spectroscopic measurement of species adsorbed on platinum(111). a Potential dependence of infrared spectra on Pt(111) and Pt(111) modified with tetra- $n$-hexylammonium cation $\left(\mathrm{THA}^{+}\right)$in $0.1 \mathrm{M}$ acidic solutions saturated with Ar. The potential of the background spectra is $0.30 \mathrm{~V}$ versus reversible hydrogen electrode (RHE). The potentials of the sample spectra are stepped in the positive direction. $\mathbf{b}$ Potential dependence of the charge density of Pt oxidation and the band intensity of $\delta_{\mathrm{PtOH}}$
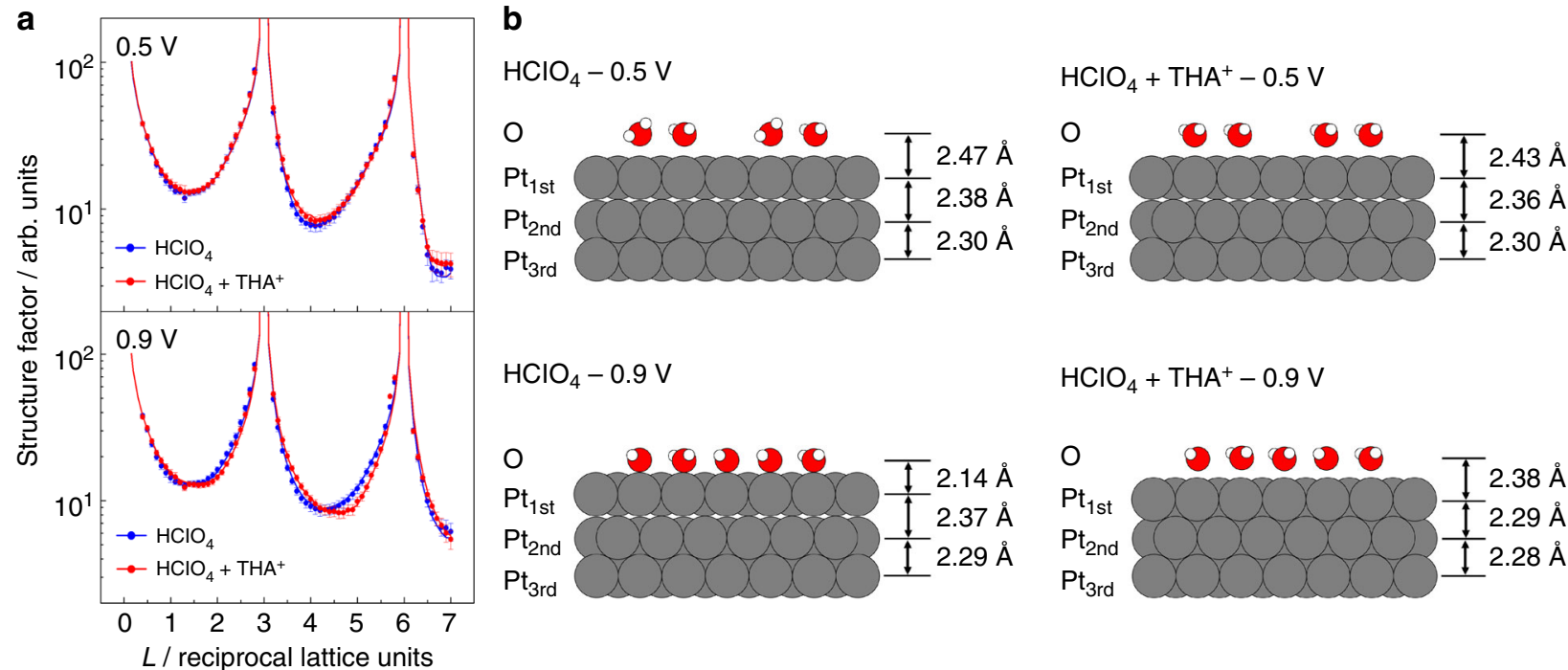

$\mathrm{HClO}_{4}-0.9 \mathrm{~V} \quad \mathrm{HClO}_{4}+\mathrm{THA}^{+}-0.9 \mathrm{~V}$
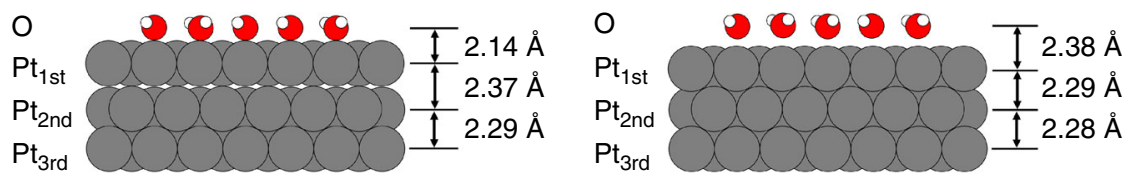

Fig. $3 \mathrm{X}$-ray crystal truncation rod measurement of interfacial structure on platinum(111). a Specular crystal truncation rod (CTR) profiles of Pt(111) in $0.1 \mathrm{M}$ $\mathrm{HClO}_{4}$ with and without $10^{-6} \mathrm{M}$ tetra-n-hexylammonium cation $\left(\mathrm{THA}^{+}\right)$saturated with $\mathrm{Ar}$ at $0.50 \mathrm{~V}$ and $0.90 \mathrm{~V}$ versus reversible hydrogen electrode (RHE). The dots are the data points and the solid lines are the structure factors calculated using the optimized model. $\mathbf{b}$ Schematic models of the interfacial structure

cation and its hydration shell. The hydronium cation facilitates the construction of a tetrahedral configuration, stabilizing the ice-like structure $^{24,33}$. Conversely, the hydration shell around hydrophobic cations such as $\mathrm{THA}^{+}$disrupts the tetrahedral hydrogen-bonding network. As a consequence, the monomeric species may be stabilized on the surface.

$\mathrm{X}$-crystal truncation rod measurement of interfacial structures. Electron density profiles along the surface normal direction were estimated from X-ray specular crystal truncation rod (CTR) scattering. Figure 3 a shows the specular CTR profiles of $\mathrm{Pt}(111)$ in $0.1 \mathrm{M} \mathrm{HClO}_{4}$ with and without $10^{-6} \mathrm{M} \mathrm{THA}^{+}$. The CTR profiles were obtained at 0.5 and $0.9 \mathrm{~V}$, which are the double layer and the $\mathrm{OH}$ adsorption regions, respectively. Normalized CTR profiles are shown in Supplementary Figure 5a. While the CTR profiles with and without $\mathrm{THA}^{+}$at $0.50 \mathrm{~V}$ are nearly identical, the CTR at $0.90 \mathrm{~V}$ is clearly altered by the addition of $\mathrm{THA}^{+}$. Since $\mathrm{THA}^{+}$is composed of nitrogen, carbon, and hydrogen, the electron density in the EDL is significantly lower than that of Pt. Therefore, the primary factor for this variation in the CTR is the structural change in the substrate Pt. The initial model used for structural optimization comprises three Pt layers and one oxygen layer of water molecule or $\mathrm{OH}_{\mathrm{ad}}$ layer. The vertical atomic position, occupancy factor, and Debye-Waller factors for the Pt. and oxygen layers were optimized by the least-squares method. The electron density profiles and the structural parameters of the optimized model are shown in Supplementary Figure 5b and Supplementary Table 1, respectively.

Schematic models of the interfacial structure are shown in Fig. 3b. At $0.50 \mathrm{~V}$, the layer distance between oxygen and the 1 st 


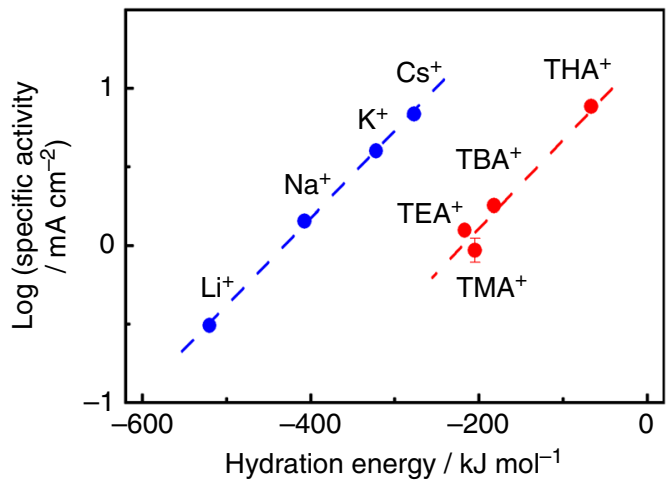

Fig. 4 Specific oxygen reduction reaction activities and hydration energies of cations. Logarithm of the specific oxygen reduction reaction (ORR) activities versus hydration energies of alkali metal cations ${ }^{19}$, tetramethylammonium cation $\left(\mathrm{TMA}^{+}\right)$, tetraethylammonium cation $\left(\mathrm{TEA}^{+}\right)$, tetra-n-

butylammonium cation $\left(\mathrm{TBA}^{+}\right)$, and tetra-n-hexylammonium cation $\left(\mathrm{THA}^{+}\right)$. The hydration energies of tetraalkylammonium cations were calculated using a following equation: $\Delta_{\text {hydr }} H^{\circ}\left(\left[\mathrm{H}\left(\mathrm{CH}_{2}\right)_{n}\right]_{4} \mathrm{~N}^{+}\right)=-172-42.4 n+10 n^{2} 25$

Pt $\left(d_{\mathrm{O}-1 \mathrm{stPt}}\right)$ is $\sim 2.43-2.47 \AA$ in both solutions. Therefore, the oxygen species are assigned to the adsorbed water at the on-top site on $\mathrm{Pt}(111)$. A similar bond length between water oxygen and $\mathrm{Pt}$ is proposed by X-ray measurements and DFT calculations ${ }^{20,34-36}$. The layer distance between 1 st and 2 nd $\mathrm{Pt}$ $\left(d_{1 \mathrm{stPt}-2 \mathrm{ndPt}}=2.36-2.38 \AA\right)$ expands by $4-5 \%$ of the bulk layer $\left(d_{\text {bulk }}=2.27 \AA\right)$. This surface relaxation is caused by charge transfer from the adsorbed water to Pt and the electric field ${ }^{37}$. The coverage of oxygen species $\left(\theta_{\mathrm{O}}\right)$ slightly increases for the $\mathrm{THA}^{+}$containing solution. IR measurements of interfacial water have been performed by many researchers, revealing that the orientation of the adsorbed water and the hydrogen-bonding networks are altered by the interaction with the electrolyte ions $^{38,39}$. The increase of the coverage indicates the existence of $\mathrm{THA}^{+}$at the interface. The IR spectra in Fig. 2a show that $\mathrm{OH}_{\mathrm{ad}}$ is not adsorbed at $0.50 \mathrm{~V}$. However, the negative-going band at $1610 \mathrm{~cm}^{-1}$ for adsorbed water on $\mathrm{Pt}(111)$ without $\mathrm{THA}^{+}$is larger than that with $\mathrm{THA}^{+}$. This fact indicates that the coverage of adsorbed water $\theta_{\mathrm{O}}$ on $\mathrm{Pt}(111)$ with $\mathrm{THA}^{+}$is higher than that without $\mathrm{THA}^{+}$in $0.1 \mathrm{M} \mathrm{HClO}_{4}$.

At $0.9 \mathrm{~V}$, The $d_{\mathrm{O}-1 \mathrm{stPt}}$ in $\mathrm{HClO}_{4}$ solution decreases from $2.47 \AA$ to $2.14 \AA$. This corresponds to the $\mathrm{Pt}-\mathrm{O}$ bond length of $\mathrm{OH}_{\mathrm{ad}}$ on $\mathrm{Pt}(111)$ proposed by low-energy electron diffraction and in situ Xray diffraction measurements ${ }^{34,40}$. Potential-dependent coadsorbed structures of water and $\mathrm{OH}_{\text {ad }}$ were suggested by DFT calculations and Monto Carlo simulations ${ }^{41,42}$. XPS measurements also indicate the coadsorption of water and $\mathrm{OH}_{\mathrm{ad}}{ }^{14}$, hence the coverage at $0.90 \mathrm{~V}\left(\theta_{\mathrm{O}}=0.78\right)$ includes adsorbed water and $\mathrm{OH}$ species. The surface relaxation of the Pt layer is promoted by electron donation via an oxygen lone pair of the $\mathrm{OH}_{\mathrm{ad}}$ as well as adsorbed water ${ }^{43}$. Therefore, $d_{1 \text { stPt-2ndPt }}$ is comparable with that at $0.50 \mathrm{~V}$. Conversely, in the presence of $\mathrm{THA}^{+}, d_{\mathrm{O}-1 \mathrm{stPt}}$ is $2.38 \AA$, which indicates that adsorbed water is dominant instead of $\mathrm{OH}_{\mathrm{ad}}$. It is notable that the surface relaxation is eliminated $\left(d_{1 \text { stPt-2ndPt }}=\right.$ $2.29 \AA$ ) even though the water and $\mathrm{OH}_{\mathrm{ad}}$ are adsorbed on Pt. This result indicates that the interaction between the oxygen species and $\mathrm{Pt}$ is decreased by the presence of $\mathrm{THA}^{+}$.

\section{Discussion}

The enhancement of the ORR activity by the addition of $\mathrm{TAA}^{+}$is related with the hydrophobicity of $\mathrm{TAA}^{+}$. Figure 4 shows the correlation between hydration enthalpy and the ORR activity. A linear correlation is found except $\mathrm{TMA}^{+}$, and the slope for $\mathrm{TAA}^{+}$ is similar to that for alkali metal cations, as reported by Markovic et al. ${ }^{19}$. They suggested that the non-covalent interaction between hydrated cations and $\mathrm{OH}_{\mathrm{ad}}$ affects electrocatalytic reaction on $\mathrm{Pt}^{19,44,45}$. In alkaline solution, the ORR activity is related to the hydration energy of alkali metal cation because cations with a strong affinity for adsorbed oxygen species block the active sites for the ORR. The order of the hydration energy of alkali metal cations $\left(\mathrm{Li}^{+} \gg ; \mathrm{Na}^{+}>\mathrm{K}^{+}>\mathrm{Cs}^{+}\right)$is inversely correlated to the ORR activity $\left(\mathrm{Cs}^{+}>\mathrm{K}^{+}>\mathrm{Na}^{+}\right.$" $\left.\mathrm{Li}^{+}\right)$. Previous $\mathrm{IR}$ and $\mathrm{X}$-ray studies have revealed that $\mathrm{Li}^{+}$located at the OHP inhibits the surface oxidation of $\mathrm{Pt}(111)$ due to the stabilization effect between $\mathrm{Li}^{+}$and $\mathrm{OH}_{\mathrm{ad}}$, whereas high-order oxidation accompanied by surface roughness proceeds in solution containing Cs ${ }^{+20}$. Thus, $\mathrm{OH}_{\mathrm{ad}}$ is stabilized by the interaction with species that have high-oxygen affinity. The hydration structures of interfacial cations were assumed from the $\mathrm{OH}$ stretching band frequency ${ }^{21,22}$. The hydration water around hydrophilic cations, such as $\mathrm{H}^{+}$and $\mathrm{Li}^{+}$, is coordinated with the dipole moment pointed outward and the hydrogen atoms of the hydration water, which can link with the oxygen species located in the secondary hydration sphere. Conversely, hydrophobic cations such as $\mathrm{TAA}^{+}$weaken the bonding with hydration water and strengthen intermolecular hydrogen bonding in the primary hydration shell. Consequently, the hydration shell around the hydrophobic cation is restricted to coordination with the outer oxygen species because of the complete hydrogen-bonding network within the shell. The ORR activity in $\mathrm{TMA}^{+}$is comparable with that in $\mathrm{HClO}_{4}$ without $\mathrm{TAA}^{+}$, indicating that $\mathrm{TMA}^{+}$does not contribute the enhancement of the ORR. Since the hydration shell size of $\mathrm{TMA}^{+}$is smaller than those of the other $\mathrm{TAA}^{+}$, the complete hydrogen-bonding network may not be constructed in the shell.

The OHP cations interact with the charged species in the EDL as well as the substrate. Therefore, cations electrostatically interacting with adsorbed anions can approach the surface at the potentials more positive than the potential of zero charge (pzc) $)^{17,20,46,47}$. The coverage of the OHP cations is balanced with that of the adsorbed anions and the surface charge depending on the electrode potential. On the surface at a constant coverage of adsorbed counter anions, the coverage of the OHP cation decreases with increasing potential ${ }^{17}$. As described above, the IR spectra indicate that the coverage of $\mathrm{THA}^{+}$is approximately constant in the potential region examined in this study. The increase in the coverage of the negatively charged species, i.e., $\mathrm{OH}_{\mathrm{ad}}$ and $\mathrm{O}_{\mathrm{ad}}$, is balanced by positive surface charge so that the coverage of the $\mathrm{THA}^{+}$remains constant.

While the ORR activity on $\mathrm{Pt}(111)$ is dramatically enhanced by the presence of $\mathrm{THA}^{+}$, there is no significant enhancement of the ORR on $\mathrm{Pt}(100), \mathrm{Pt}(110)$ and $\mathrm{Pt}(331)$ by $\mathrm{THA}^{+}$. In acidic solution above $0.6 \mathrm{~V}$, the hydration water around $\mathrm{H}^{+}$is linked with $\mathrm{OH}_{\mathrm{ad}}$ through hydrogen bond (Fig. 5a). $\mathrm{H}^{+}-\mathrm{H}_{2} \mathrm{O}-\mathrm{OH}_{\mathrm{ad}}$ formation stabilizes the $\mathrm{OH}_{\text {ad }}$ layer and inhibits the ORR. According to studies on the $\mathrm{Pt}(111)$ surface under the ultra-high vacuum condition, the coadsorption of $\mathrm{OH}_{\mathrm{ad}}$ and $\mathrm{H}_{2} \mathrm{O}$ forms a well-defined $3 \times 3$ honeycomb structure because the symmetry and $\mathrm{OH}$... $\mathrm{O}$ distance in the coadsorbed layer fit well with the $\operatorname{Pt}(111)$ lattice $^{14,48}$. The approach of the hydration shell around $\mathrm{THA}^{+}$to the Pt surface disrupts the stabilization effect between the hydration water and the $\mathrm{OH}_{\mathrm{ad}}$ layer (Fig. 5b). The coverage of $\mathrm{OH}_{\mathrm{ad}}$ is decreased by this destabilization effect, which induces the disruption of stable hydrogen-bonding network in the coadsorbed layer. These multiple effects are enhanced by the hydrophobicity of cation and promote the access of oxygen molecules to the $\mathrm{Pt}(111)$ surface.

The IR spectra on $\mathrm{Pt}(100)$ indicate that the addition of $\mathrm{THA}^{+}$ results in a slight reduction of the band intensity and band broadening of $\delta_{\mathrm{PtOH}}$ as shown in Supplementary Figure 6. The charge densities for surface oxidation also decrease on $\mathrm{Pt}(110)$ and $\mathrm{Pt}(331)$ above $0.7 \mathrm{~V}$ after the addition of $\mathrm{THA}^{+}$. For $\mathrm{Pt}(100)$, 
a

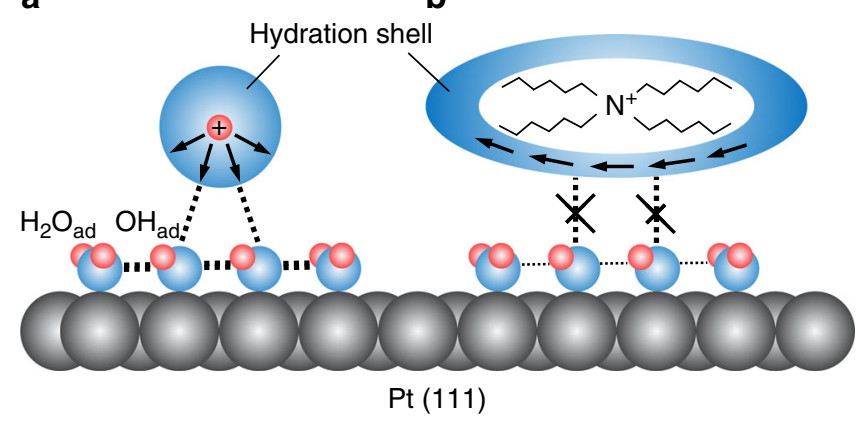

Fig. 5 Schematic of interfacial hydrated cations and adsorbed hydroxide species. a hydrophilic cation and (b) hydrophobic cation. Arrows indicate the direction of water dipole within the hydration shell. (Platinum is represented by gray spheres, oxygen by blue spheres, and hydrogen by pink spheres.)

$\mathrm{Pt}(110)$, and $\mathrm{Pt}(331)$, although $\mathrm{OH}$ adsorption is inhibited by the approach of the $\mathrm{THA}^{+}$hydration shell, the ORR enhancement effect by the disruption of $\mathrm{OH}_{\mathrm{ad}}+\mathrm{H}_{2} \mathrm{O}$ hydrogen-bonding network is weak due to the narrow (111) terrace and the lattice mismatch of the $\mathrm{OH}_{\mathrm{ad}}+\mathrm{H}_{2} \mathrm{O}$ honeycomb layer with the substrate. The $\mathrm{Pt}(331)$ surface having a (111) terrace shows highORR activity in $\mathrm{HClO}_{4}$ without $\mathrm{TAA}^{+}{ }^{+}$. DFT calculations suggest that the $\mathrm{OH}_{\mathrm{ad}}$ on stepped Pt surfaces is destabilized by deforming the hydrogen bonds of interfacial water surrounding the adsorption sites, and the destabilization of oxygen species cause the enhancement of the ORR on the (111) terrace ${ }^{49}$.

The ORR activity on $\mathrm{Pt}(111)$ in $\mathrm{THA}^{+}$is comparable with those on $\mathrm{Pt}_{3} \mathrm{Co}(111)$ and $\mathrm{Pt}_{3} \mathrm{Ni}(111)$ in $\mathrm{HClO}_{4}$. The activation factor for the ORR with these Pt alloys is also due to decrease in the coverage of $\mathrm{OH}_{\mathrm{ad}}$. Therefore, a similar inhibiting effect of $\mathrm{OH}_{\mathrm{ad}}$ can be achieved by the structural improvement in EDL species. Furthermore, the supply of oxygen molecules to the electrode may be improved by weakening the hydrogen-bonding strength around the hydrophobic cations.

In summary, we evaluated the ORR activities of single-crystal Pt electrodes in $\mathrm{HClO}_{4}$ solutions containing $\mathrm{TAA}^{+}$with various alkyl chain lengths. The ORR activity increased in the following sequence $\mathrm{THA}^{+} n=6 » \mathrm{TBA}^{+} n=4>\mathrm{TEA}^{+} n=2>\mathrm{TMA}^{+}$ $n=1 \approx \mathrm{HClO}_{4}$, and the ORR activity on $\mathrm{Pt}(111)$ in $\mathrm{THA}^{+}$was comparable with those on $\mathrm{Pt}_{3} \mathrm{Co}(111)$ and $\mathrm{Pt}_{3} \mathrm{Ni}(111)$ in $\mathrm{HClO}_{4}$. In situ IR and X-ray CTR measurements indicated that the coverage of $\mathrm{OH}_{\mathrm{ad}}$ on $\mathrm{Pt}(111)$ at $0.90 \mathrm{~V}$ in the presence of $\mathrm{THA}^{+}$is decreased. The weaker interaction between the hydration shell around THA ${ }^{+}$and $\mathrm{OH}_{\mathrm{ad}}$ destabilizes the $\mathrm{OH}_{\mathrm{ad}}+\mathrm{H}_{2} \mathrm{O}$ coadsobed layer and forms a highly efficient interface for the ORR.

\footnotetext{
Methods

Electrochemical measurement. Single-crystal Pt beads for CV measurement were prepared by the Clavilier's method ${ }^{50}$. The crystal beads were oriented to (111), (100), (110), and (331) using Laue back reflection of X-ray, and then mechanically polished with diamond slurries ${ }^{51}$. A Pt(111) disk ( $8 \mathrm{~mm}$ in diameter, MaTech) was used for the X-ray CTR measurement. The samples were annealed in $\mathrm{H}_{2}+\mathrm{O}_{2}$ flame, and then cooled to room temperature in $\mathrm{Ar}+\mathrm{H}_{2}$ or $\mathrm{Ar}$ atmosphere. The annealed surfaces were protected with ultrapure water (Milli-Q Advantage A10, Millipore). The solutions were prepared with $\mathrm{HClO}_{4}$ (Kanto Chemical), HF (Kanto Chemical), tetraalkylammonium salts, and ultrapure water. The tetraalk-

ylammonium salts used were tetramethylammonium perchlorate (Tokyo Chemical Industry), tetraethylammonium perchlorate (Tokyo Chemical Industry), tetra- $n-$ butylammonium perchlorate (Sigma-Aldrich), and tetra- $n$-hexylammonium perchlorate (Alfa Aesar). The reference electrode used in all measurements was a reversible hydrogen electrode (RHE). The ORR voltammograms were measured in the hanging meniscus rotating disk electrode (RDE) configuration using an electrochemical analyzer (ALS 701DH, BAS) and a rotating ring-disk electrode apparatus (RRDE-3 A, BAS) ${ }^{52}$. The ORR activity was estimated from the kinetic current density (specific activity, $j_{\mathrm{k}}$ ) at $0.90 \mathrm{~V}$ versus RHE according to the Koutecky-Levich equation: $1 / j=1 / j_{\mathrm{k}}+1 / j_{\mathrm{L}}$, where $j$ and $j_{\mathrm{L}}$ are the total current density
}

and the limiting current density, respectively. The current densities were normalized to the geometrical surface area of the Pt surface.

Infrared spectroscopy. In situ infrared reflection absorption spectroscopy (IRAS) measurement was performed using an Fourier transform (FTIR) spectrometer (Bruker Vertex $70 \mathrm{v}$ ). An electrochemical IR cell with a trapezoid $\mathrm{BaF}_{2}$ or $\mathrm{CaF}_{2}$ window beveled at $60^{\circ}$ was attached to the spectrometer with a narrow band mercury-cadmium-telluride (MCT) detector. A polypropylene film (Chemplex Industries) with a thickness of $6 \mu \mathrm{m}$ was intercalated between the $\mathrm{BaF}_{2}$ prism and the $\mathrm{Pt}(111)$ and $\mathrm{Pt}(100)$ surfaces to prevent the dissolution of the $\mathrm{BaF}_{2}$ material ${ }^{20}$. A layer of water was placed between the $\mathrm{BaF}_{2}$ prism and the polymer film to compensate for the gap of the refractive index. The interferograms were averaged over 640 scans by subtractively normalized interfacial FTIR (SNIFTIRS) with ppolarized light at a resolution of $4 \mathrm{~cm}^{-1}$. In $\mathrm{THA}^{+}$-containing solution, the adsorption of $\mathrm{OH}_{\mathrm{ad}}$ is inhibited by the repetitive potential steps of SNIFTIRS measurement because $\mathrm{THA}^{+}$assembles on the surface at the negative potentials. Therefore, after the $\mathrm{Pt}(111)$ and $\mathrm{Pt}(100)$ electrodes were immersed in $0.1 \mathrm{M} \mathrm{HClO}_{4}$ and $0.1 \mathrm{M} \mathrm{HF}$ containing $\mathrm{THA}^{+}$for $5 \mathrm{~min}$, IR measurement was performed in the solution without $\mathrm{THA}^{+}$. We confirmed that $\mathrm{Pt}(111)$ modified with $\mathrm{THA}^{+}$shows the same voltammograms and ORR activity.

X-ray crystal truncation rod scattering. In situ X-ray CTR measurement was performed with a multi-axis diffractometer at BL13XU (SPring- 8$)^{53}$. The X-ray energy used was $20 \mathrm{keV}$. Integrated intensities were measured by rocking scans, and then corrected for Lorentz and area factors. Specular CTR was measured along the surface normal direction $L$ in units of $\mathbf{c}^{\star}=2 \pi / \mathbf{c},|\mathbf{c}|=0.6797 \mathrm{~nm}$. Structure refinements were conducted using the least-squares method with the ANA-ROD program ${ }^{54}$.

\section{Data availability}

The data that support the findings of this study are available within the paper and Supplementary Information, as well as from the corresponding author upon request.

Received: 29 April 2018 Accepted: 4 October 2018

Published online: 05 November 2018

\section{References}

1. Zhang, C., Shen, X., Pan, Y. \& Peng, Z. A review of Pt-based electrocatalysts for oxygen reduction reaction. Front. Energy 11, 268-285 (2017).

2. Lv, H. et al. Recent advances in the design of tailored nanomaterials for efficient oxygen reduction reaction. Nano Energy 29, 149-165 (2016).

3. Gomez-Marin, A. M., Rizo, R. \& Feliu, J. M. Oxygen reduction reaction at Pt single crystals: a critical overview. Catal. Sci. Technol. 4, 1685-1698 (2014).

4. Stamenkovic, V. et al. Changing the activity of electrocatalysts for oxygen reduction by tuning the surface electronic structure. Angew. Chem. Int. Ed. 45 2897-2901 (2006).

5. Strasser, P. et al. Lattice-strain control of the activity in dealloyed core-shell fuel cell catalysts. Nat. Chem. 2, 454-460 (2010).

6. Stamenkovic, V. R. et al. Improved oxygen reduction activity on $\mathrm{Pt}_{3} \mathrm{Ni}(111)$ via increased surface site availability. Science 315, 493-497 (2007).

7. Kobayashi, S., Wakisaka, M., Tryk, D. A., Iiyama, A. \& Uchida, H. Effect of alloy composition and crystal face of Pt-skin/ $\mathrm{Pt}_{100-X} \mathrm{Co}_{X}[(111),(100)$, and (110)] single crystal electrodes on the oxygen reduction reaction activity. J. Phys. Chem. C. 121, 11234-11240 (2017).

8. Kuzume, A., Herrero, E. \& Feliu, J. M. Oxygen reduction on stepped platinum surfaces in acidic media. J. Electroanal. Chem. 599, 333-343 (2007).

9. Sugimura, F., Nakamura, M. \& Hoshi, N. The oxygen reduction reaction on kinked stepped surfaces of Pt. Electrocatalysis 8, 46-50 (2017).

10. Calle-Vallejo, F. et al. Why conclusions from platinum model surfaces do not necessarily lead to enhanced nanoparticle catalysts for the oxygen reduction reaction. Chem. Sci. 8, 2283-2289 (2017).

11. Markovic, N. M., Gasteiger, H. A., Grgur, B. N. \& Ross, P. N. Oxygen reduction reaction on $\mathrm{Pt}(111)$ : effects of bromide. J. Electroanal. Chem. 467, 157-163 (1999).

12. Stamenkovic, V. R., Markovic, N. M. \& Ross, P. N. Structure-relationships in electrocatalysis: oxygen reduction and hydrogen oxidation reactions on $\mathrm{Pt}$ (111) and $\mathrm{Pt}(100)$ in solutions containing chloride ions. J. Electroanal. Chem. 500, 44-51 (2001)

13. Wang, J. X., Markovic, N. M. \& Adzic, R. R. Kinetic analysis of oxygen reduction on $\mathrm{Pt}(111)$ in acid solutions: intrinsic kinetic parameters and anion adsorption effects. J. Phys. Chem. B 108, 4127-4133 (2004).

14. Wakisaka, M., Udagawa, Y., Suzuki, H., Uchida, H. \& Watanabe, M. Structural effects on the surface oxidation processes at Pt. single-crystal electrodes 
studied by X-ray photoelectron spectroscopy. Energy Environ. Sci. 4, 1662-1666 (2011).

15. Tanaka, $\mathrm{H}$. et al. Infrared reflection absorption spectroscopy of $\mathrm{OH}$ adsorption on the low index planes of Pt. Electrocatalysis 6, 295-299 (2015).

16. Ueno, T. et al. Infrared spectrocsopy of adsorbed $\mathrm{OH}$ on $n(111)-(100)$ and $n(111)-(111)$ series of Pt electrode. J. Electroanal. Chem. 800, 162-166 (2017).

17. Nakamura, M., Sato, N., Hoshi, N. \& Sakata, O. Outer Helmholtz plane of the electrical double layer formed at the solid liquid interface. ChemPhysChem 12, 1430-1434 (2011).

18. Nakamura, M., Nakajima, Y., Sato, N., Hoshi, N. \& Sakata, O. Structure of the electrical double layer on $\mathrm{Ag}(100)$ : promotive effect of cationic species on $\mathrm{Br}$ adlayer formation. Phys. Rev. B 84, 165433 (2011).

19. Strmcnik, D. et al. The role of non-covalent interactions in electrocatalytic fuel-cell reactions on platinum. Nat. Chem. 1, 466-472 (2009).

20. Nakamura, M., Nakajima, Y., Hoshi, N., Tajiri, H. \& Sakata, O. Effect of nonspecifically adsorbed ions on the surface oxidation of $\mathrm{Pt}(111)$. ChemPhysChem 14, 2426-2431 (2013).

21. Yamakata, A. \& Osawa, M. Destruction of the water layer on a hydrophobic surface induced by the forced approach of hydrophilic and hydrophobic cations. J. Phys. Chem. Lett. 1, 1487-1491 (2010).

22. Yamakata, A. \& Osawa, M. Cation-dependent restructure of the electric double layer on CO-covered Pt electrodes: difference between hydrophilic and hydrophobic cations. J. Electroanal. Chem. 800, 19-24 (2016).

23. Dunwell, M., Wang, J. \& Xu, B. Surface enhanced spectroscopic investigations of adsorption of cations on electrochemical interfaces. Phys. Chem. Chem. Phys. 19, 971-975 (2017).

24. Skulason, E. et al. Density functional theory calculations for the hydrogen evolution reaction in an electrochemical double layer on the $\mathrm{Pt}(111)$ electrode. Phys. Chem. Chem. Phys. 9, 3241-3250 (2007).

25. Marcus, Y. Tetraalkylammonium ions in aqueous and non-aqueous solutions. J. Solut. Chem. 37, 1071-1098 (2008).

26. Osawa, M., Tsushima, M., Mogami, H., Samjeske, G. \& Yamakata, A. Structure of water at the electrified platinum-water interface: a study by surface-enhanced infrared absorption spectroscopy. J. Phys. Chem. C. 112, 4248-4256 (2008).

27. Nakamura, M., Kato, H. \& Hoshi, N. Infrared spectroscopy of water adsorbed on $\mathrm{M}(111)(\mathrm{M}=\mathrm{Pt}, \mathrm{Pd}, \mathrm{Rh}, \mathrm{Au}, \mathrm{Cu})$ electrodes in sulfuric acid solution. J. Phys. Chem. C. 112, 9458-9463 (2008).

28. Bentwood, R. M., Barnes, A. J. \& Orville-Thomas, W. J. Studied of intermolecular interactions by matrix isolation vibrational spectroscopy: Selfassociation of water. J. Mol. Spectrosc. 84, 391-404 (1980).

29. Nakamura, M. \& Ito, M. Ring hexamer like cluster molecules of water formed on a Ni(l 111$)$ surface. Chem. Phys. Lett. 384, 256-261 (2004).

30. Yamamoto, S., Beniya, A., Mukai, K., Yamashita, Y. \& Yoshinobu, J. Water adsorption on $\mathrm{Rh}(111)$ at $20 \mathrm{~K}$ : from monomer to bulk amorphous ice. J. Phys. Chem. B 109, 5816-5823 (2005).

31. Nakamura, M. \& Ito, M. Infrared spectroscopic study of water coadsorbed with $\mathrm{Na}$ on the $\mathrm{Ru}(001)$ surface. Surf. Sci. 502-503, 144-148 (2002).

32. Motobayashi, K. et al. Adsorption of water dimer on platinum(111): identification of the -OH...Pt. hydrogen bond. ACS Nano 8, 11583-11590 (2014).

33. Shingaya, Y. \& Ito, M. Coordination number and molecular orientation of hydronium cation/bisulfate anion adlayers on $\mathrm{Pt}(111)$. Surf. Sci. 368, 318-323 (1996).

34. Kondo, T., Masuda, T., Aoki, N. \& Uosaki, K. Potential-dependent structures and potential-induced structure changes at $\mathrm{Pt}(111)$ single-crystal electrode/ sulfuric and perchloric acid interface in the potential region between hydrogen underpotential deposition and surface oxide formation by in situ surface Xray scattering. J. Phys. Chem. C. 120, 16118-16131 (2016).

35. Michaelides, A., Ranea, V. A., de Andres, P. L. \& King, D. A. General model for water monomer adsorption on close-packed transition and noble metal surfaces. Phys. Rev. Lett. 90, 216102 (2003).

36. Meng, S., Wang, E. G. \& Gao, S. Water adsorption on metal surfaces: a general picture from density functional theory studies. Phys. Rev. B 69, 195404 (2004).

37. Grunder, Y. \& Lucas, C. A. Surface X-ray diffraction studies of single crystal electrocatalysts. Nano Energy 29, 378-393 (2016).

38. Hirota, K., Song, M. -B. \& Ito, M. In-situ infrared spectroscopy of water and electrolytes adsorbed on a $\mathrm{Pt}(111)$ electrode surface in acid solution. Structural changes of adsorbed water molecules upon an electrode potential. Chem. Phys. Lett. 250, 335-341 (1996).

39. Arihara, K., Kitamura, F., Ohsaka, T. \& Tokuda, K. Characterization of the adsorption state of carbonate ions at the $\mathrm{Au}(111)$ electrode surface using in situ IRAS. J. Electroanal. Chem. 510, 128-135 (2001).

40. Seitsonen, A. P., Zhu, Y., Bedurftig, K. \& Over, H. Bonding mechanism and atomic geometry of an ordered hydroxyl overlayer on Pt(111). J. Am. Chem. Soc. 123, 7347-7351 (2001).

41. Rai, V., Aryanpour, M. \& Pitsch, H. First-principle analysis of oxygencontaining adsorbates formed from the electrochemical discharge of water on Pt(111). J. Phys. Chem. C. 112, 9760-9768 (2008).
42. Chen, J., Luo, S., Liu, Y. \& Chen, S. The oretical analysis of electrochemical formation and phase transition of oxygenated adsorbates on $\mathrm{Pt}(111)$. ACS Appl. Mater. Interfaces 8, 20448-20458 (2016).

43. Fowler, B. et al. Segregation and stability at $\mathrm{Pt}_{3} \mathrm{Ni}(111)$ surfaces and $\mathrm{Pt}_{75} \mathrm{Ni}_{25}$ nanoparticles. Electrochim. Acta 53, 6076-6080 (2008).

44. Strmcnik, D. et al. Effects of $\mathrm{Li}^{+}, \mathrm{K}^{+}$, and $\mathrm{Ba}^{2+}$ cations on the ORR at model and high surface area Pt and Au surfaces in alkaline solutions. J. Phys. Chem. Lett. 2, 2733-2736 (2011).

45. Lopes, P. P. et al. Double layer effects in electrocatalysis: the oxygen reduction reaction and ethanol oxidation reaction on $\mathrm{Au}(111), \mathrm{Pt}(111)$ and $\operatorname{Ir}(111)$ in alkaline media containing $\mathrm{Na}$ and Li cations. Catal. Today 262, 41-47 (2016).

46. Lucas, C. A., Thompson, P., Grunder, Y. \& Markovic, N. M. The structure of the electrochemical double layer: $\mathrm{Ag}(111)$ in alkaline electrolyte. Electrochem. Commun. 13, 1205-1208 (2011)

47. Keller, H., Saracino, M., Nguyen, H. M. T., Huynh, T. M. T. \& Broekmann, P. Competitive anion/water and cation/water interactions at electrified copper/ electrolyte interfaces probed by in situ X-ray diffraction. J. Phys. Chem. C. 116, 11068-11076 (2012).

48. Clay, C., Haq, S. \& Hodgson, A. Hydrogen bonding in mixed $\mathrm{OH}+\mathrm{H} 2 \mathrm{O}$ overlayers on Pt(111). Phys. Rev. Lett. 92, 046102 (2004).

49. Jinnouchi, R., Kodama, K. \& Morimoto, Y. DFT calculations on $\mathrm{H}, \mathrm{OH}$ and $\mathrm{O}$ adsorbate formations on $\operatorname{Pt}(111)$ and $\operatorname{Pt}(332)$ electrodes. J. Electroanal. Chem. 716, 31-44 (2014).

50. Clavilier, J., Faure, R., Guinet, G. \& Durand, R. Preparation of monocrystalline Pt microelectrodes and electrochemical study of the plane surfaces cut in the direction of the $\{111\}$ and $\{110\}$ planes. J. Electroanal. Chem. 107, 205-209 (1980).

51. Furuya, N. \& Koide, S. Hydrogen adsorption on platinum single-crystal surfaces. Surf. Sci. 220, 18-28 (1989).

52. Cahan, B. D. \& Villulas, H. M. The hanging meniscus rotating disk (HMRD). J. Electroanal. Chem. 307, 263-268 (1991).

53. Sakata, O. et al. Beamline for surface and interface structures at SPring-8. Surf. Rev. Lett. 10, 543-547 (2003).

54. Vlieg, E. ROD: a program for surface X-ray crystallography. J. Appl. Crystallogr. 33, 401-405 (2000)

\section{Acknowledgements}

X-ray measurements were supported by JASRI/SPring-8 (2016A1287 and 2017B1293). This work was supported by the Asahi Glass Foundation, JSPS KAKENHI Grant Number 2435001 and $15 \mathrm{H} 03763$, and NEDO.

\section{Author contributions}

M.N. designed the study. T.K. performed the electrochemical measurements. M.N. and T.K. performed the IR measurements. M.N., T.K., H.T. and O.S. performed the X-ray CTRs measurements. M.N., T.K. and N.H. discussed the Results. M.N. and T.K. co-wrote the paper with contributions from all authors.

\section{Additional information}

Supplementary Information accompanies this paper at https://doi.org/10.1038/s41467018-06917-4.

Competing interests: The authors declare no competing interests.

Reprints and permission information is available online at http://npg.nature.com/ reprintsandpermissions/

Publisher's note: Springer Nature remains neutral with regard to jurisdictional claims in published maps and institutional affiliations.

Open Access This article is licensed under a Creative Commons Attribution 4.0 International License, which permits use, sharing, adaptation, distribution and reproduction in any medium or format, as long as you give appropriate credit to the original author(s) and the source, provide a link to the Creative Commons license, and indicate if changes were made. The images or other third party material in this article are included in the article's Creative Commons license, unless indicated otherwise in a credit line to the material. If material is not included in the article's Creative Commons license and your intended use is not permitted by statutory regulation or exceeds the permitted use, you will need to obtain permission directly from the copyright holder. To view a copy of this license, visit http://creativecommons.org/ licenses/by/4.0/

(C) The Author(s) 2018 